\title{
Student Engagement and Deep Learning in the First-Year International Relations Classroom: Simulating a UN Security Council Debate on the Syrian Crisis
}

\author{
Lucy West and Dan Halvorson \\ Griffith University \\ Queensland, Australia
}

\begin{abstract}
This article evaluates a 'real-time' simulation where students role-play a United Nations Security Council (UNSC) negotiation over humanitarian intervention in Syria. This simulation is undertaken in a large introductory International Relations (IR) subject. The article argues that in order to achieve deep learning outcomes across the diverse, contemporary cohort of first-year university students, active learning approaches need to be employed that engage differing learning styles and preferences. Deep learning is assessed across the conceptual and metacognitive knowledge domains with two indicators: (1) students' understanding of IR concepts by applying them beyond the parameters of the Syria case; and (2) students' critical reflection on their moral reasoning elicited by the task. We evaluate 820 students across six cohorts and 21 iterations of the simulation during 2016 and 2017 with a survey instrument and formal reflection assignment. The article finds that the simulation is highly effective at consistently engaging the majority of students' interest and motivation, while illustrating the acute and sometimes tragic tension between moral and political reasoning in International Relations. We found that disrupting student's cognitive structures regarding human rights and justice stimulated not only deeper conceptual understanding, but also emotional reactions that were the catalyst for metacognitive reflection.
\end{abstract}

Key words: active learning, simulation, International Relations pedagogy, first-year university teaching

\section{Corresponding author:}

Dr Dan Halvorson

School of Government and International Relations

Griffith University

Kessels Rd, Nathan, QLD 4111, Australia

Ph: +61737356420

Email: d.halvorson@griffith.edu.au 


\section{Introduction}

It is well-established that active learning strategies such as role-play simulations are highly effective in fostering classroom engagement, considered as students' interest, enthusiasm, motivation and enjoyment in their learning (Kahu 2013: 760-63; Lawson and Lawson 2013: 435-36). Engagement with their studies is an important factor in student retention and completion of degree programs, as well as student identification with their discipline area and satisfaction with their university experience. Student engagement has become a priority for universities with the opening of higher education to large proportions of the population from non-traditional tertiary education backgrounds and pathways. First-year university classes are often very large with great student diversity and fluctuating academic ability. Research suggests that students entering university with lower educational 'capital' will be more engaged and perform best if teaching approaches align with their learning style (Waring and Evans 2015: 102), while students of high traditional academic ability can thrive across a range of learning tasks and settings (Biggs and Tang 2011: 8-11). Much of the newer cohort entering Australian universities, for example, has a preference for a kinaesthetic, or learning-by-doing approach (Crosley and Heagney 2009). Recent studies have found that well-designed simulations in the Political Science classroom can produce conceptual and metacognitive knowledge outcomes reflective of deep learning approaches across a broad section of the student cohort (Engel, Pallas and Lambert 2017).

Our teaching practice integrates student engagement through role play simulation with deep learning approaches in first-year International Relations (IR). We argue that in order to achieve deep learning outcomes across the contemporary cohort of first-year university students, active learning approaches need to be employed that engage differing learning styles and preferences. We seek to do this through a simulation of a United Nations Security Council (UNSC) debate over humanitarian intervention in the Syrian civil war. ${ }^{1} \mathrm{~A}$ problem-based, role-play simulation of this nature provides introductory learners with a positive first encounter with IR that stimulates their interest and motivation by convincing them of the 'real-world' relevance of the discipline. It does this more successfully than traditional lectures and tutorials by immersing students in the content and process of a multidimensional, 'real-time' humanitarian and security crisis (Zappile, Beers and Raymond

\footnotetext{
${ }^{1}$ This research was undertaken in accordance with Griffith University ethical guidelines.
} 
2017). The interplay between moral and political reasoning inherent in the task illustrates the perennial tension in IR between idealism and realism very effectively for first-year students. Our simulation topic illustrates most foundational IR content while the simulation design and structure engages students of different learning styles. This enables a significant proportion of introductory students to abstract from the particulars and dynamics of the classroom activities to higher levels of cognition and to broader contexts.

There are a number of ways to conceptualise deep learning approaches and assess their outcomes. The National Survey of Student Engagement (NSSE) in the United States (US) has produced a Deep Approaches to Learning Scale, which identifies three dimensions: higher-order, integrative and reflective learning (Campbell and Cabrera 2014). Pettenger, West and Young (2014) advance a set of four knowledge domains to assess deep learning outcomes in simulated negotiations: the factual, conceptual, procedural and metacognitive domains. These are integrative in that factual knowledge of the content and procedural knowledge of the task are required for higher-order conceptual knowledge. In both schema, metacognitive outcomes refer to students' ability to reflect on their learning. Engel, Pallas and Lambert (2017) use this four-part framework to assess deep learning outcomes in their model UN subject, an upper year-level core course in an IR major. The authors found that deep learning was evident across each of the four knowledge domains, with the higher order indicators of conceptual and metacognitive knowledge particularly impressive in terms of their students' understanding of IR theories and critical reflection on their learning processes.

There are a number of useful studies informing our simulation that address or touch on students' ethical development in the IR classroom (e.g., Lantis 2004; Youde 2008; Oestreich 2012; Stodden 2012), but they do not directly examine the relationship between student engagement and deep learning outcomes. Taylor (2013: 136-37) includes moral reasoning in a discussion of the educational benefits for IR students of well-designed simulations for deep learning. In a major US study of 1457 first-year liberal arts students across 19 institutions, Mayhew et al. (2012) found that students' moral reasoning can be developed through learning experiences that disrupt "existing cognitive structures for understanding justice," by engaging them with new, more complex and diverse perspectives not "easily assimilated into familiar thought patterns" (Mayhew et al. 2012: 27). The study found that active, student-centred learning environments conducive to deep learning approaches can be "mechanisms for moral reasoning development" in first-year students. 
However, they must feature "unfamiliar, external stimuli" relating to "justice and fairness" that force students to re-examine their assumptions about the world (Mayhew et al. 2012: 27-28). Our simulation case study of the Syrian civil war profoundly disrupts many student's cognitive structures and moral assumptions regarding human rights and justice in this way.

In building on this previous work, our objectives for the present study are to investigate the extent to which our simulation engages first-year students and enables them to abstract knowledge and meaning from the Syria case to understand foundational IR concepts and the inherent and sometimes tragic tension between moral and political reasoning. To this end, we assess our student knowledge outcomes on the higher-order conceptual and metacognitive domains. We evaluate deep learning across two indicators: (1) understanding IR concepts by applying them beyond the immediate parameters of the case study; and (2) metacognitive knowledge; in this case students' critical reflection on their emotional reactions and moral reasoning elicited by the task.

The evidence in this paper is drawn from the authors' experience of teaching the introductory subject, 1001GIR International Relations at Griffith University, a large multicampus public institution with 50,000 students in Queensland, Australia. At the time of writing, the Syria simulation has been undertaken 21 times by 820 students during four teaching semesters in 2016 and 2017. The subject runs with three staff members across two campuses. In workshop classes of 30 to 45 , student delegations adopt the positions of the permanent five (P-5) members of the UNSC and an International Non-Government Organisation (INGO). While INGOs have no formal status in international law, the inclusion of an INGO in this simulation design reflects the growing role that they play in the emergence, formulation and monitoring of international norms. The student cohort at Griffith University is large and diverse. For example, in Semester 1, 2016, there were 234 students enrolled in Brisbane and 145 students at Gold Coast campus for a total of 379 students. Of these, 167 were in the International Business program and completing the subject as a compulsory firstyear requirement. There were 55 other non-degree students taking the subject as an elective, leaving 157 , or less than half, completing a Political Science degree.

The article proceeds by introducing deep and surface learning approaches in the following section. It then discusses the importance of topic selection in engaging the contemporary cohort of first-year students and shows how our simulation design and learning environment are conducive to students' conceptual and metacognitive knowledge 
development. The third section analyses the data collected to evaluate the simulation for student engagement and deep learning. It concludes with reflections on improvements and future directions.

\section{Deep and Surface Learning}

The contrast between 'deep' and 'surface' learning approaches, and the teaching and learning environments that create them, is a major theme in pedagogical theory. Students employing a surface approach perceive learning tasks as an 'external imposition' and their primary goal is to adequately complete the requirements in a narrow utilitarian sense. Surface strategies identify 'signs'-key words or formulas seen as essential to gaining the 'answer' to the problem or task. Elements of the task are then treated in an unrelated manner and students 'engage' with the material for the purpose of gaining information for assessment items. Surface approaches often fail to differentiate between concepts and examples and therefore are unable to apply theory to practice (Ramsden 2003: 47; Biggs and Tang 2011: 24-26). Ramsden (1992: 46) concludes that surface approaches are "uniformly disastrous for learning."

In contrast, 'deep' approaches are intrinsically-motivated with the intention to understand and abstract meaning. Rather than looking for 'signs', the focus is on what is 'signified', such as the author's argument or the conceptual themes necessary to understand a phenomenon or solve a problem. Deep approaches relate previous knowledge to the current task and also integrate learning from other subjects. Students can distinguish concepts and arguments from evidence and are able to meaningfully relate theory to the empirical world (Ramsden 2003: 47, 52-55; Biggs and Tang 2011: 26-27). Deep learning is more enjoyable and creates a sense of ownership and mastery. Weber (2013: 136) notes that "deep learning is both intellectual and emotional," in that strong emotions and feelings can emerge from the "self-revelatory feedback" inherent to this approach. This is crucially important in our study, where student's emotional reactions to the human suffering in the Syria case prompted their metacognitive reflections on the tensions between moral and political reasoning.

Our initial intention in fostering deeper learning outcomes was to use the simulation to directly illustrate foundational IR concepts and contemporary global themes such as: state sovereignty; anarchy and the international system; the changing nature of war and security; 
international law and organisations; human rights, humanitarian intervention and the Responsibility to Protect (R2P); identity politics and the religious resurgence; and aid and development, through experiential learning. The Syria simulation places students at the centre of decision-making where they must develop and debate foreign policy positions in the context of a rapidly changing real world humanitarian and security crisis. Students have to practice negotiation, problem solving and conflict resolution skills under tight time constraints, which stimulates their creativity, innovation and understanding more effectively than in the traditional classroom. To reach an agreement on humanitarian action, students bargain with their peers and must be creative in developing potentially successful proposals in order to build consensus for a UNSC Resolution. Students have to understand their state's foreign policy position, develop humanitarian proposals consistent with this, and advance strategies for how to pass these proposals relative to the positions and policies of other groups and consistent with international law. We argue that this approach is highly beneficial to developing students higher order conceptual knowledge.

At the outset, we did not anticipate the full potential of the simulation to develop students' ethical awareness and moral reasoning. The Syrian conflict raises many enduring moral dilemmas in IR and international law; for instance, the acute tensions between state sovereignty and humanitarian intervention, national interests and R2P, and cultural relativism and universal human rights. All of these moral dilemmas prompt students to think critically about their ethical position in the world. We also came to realise that it was students' emotional reactions and empathetic responses that prompted their metacognitive reflection.

\section{Topic Selection and Simulation Design}

We use the Syrian civil war as both a real-time and problem-based simulation dealing with current and enduring problems in IR. The nature of the conflict, the involvement of multiple non-state and external state actors, and the subsequent refugee crisis, makes it both contemporary and attractive for a first-year IR cohort. The benefit of designing a real-time simulation is that because it operates "live," it "represents an ongoing situation" and "helps students engage with unfamiliar concepts in a more personal and immediate way than roleplay exercises about events in the distant past" (Zappile, Beers and Raymond 2017: 195). The changing landscape of civil war, terrorism and human displacement in the Syrian conflict enables students to experience 'first-hand' the complex factors and power relations 
influencing the formation and implementation of policies for humanitarian action. The 'realtime' nature of our Syrian simulation reflects the degree of uncertainty in international diplomacy.

There is often an assumption among academics that interactive learning activities such as simulations focus more on the potential for fun, and less on content knowledge. However, if designed with appropriate preparatory and reflective activities, and with the use of customised learning tools, role-play simulations can enhance content knowledge for students of all learning styles. Simulations have the flexibility to do this by creating multiple roles, tasks and responsibilities that are adaptive to variations in student learning preferences and levels of commitment. We argue that our simulation environment enables deep learning approaches with higher order learning outcomes that traditional lectures and tutorials cannot provide.

There are various simulation topics available depending on the concepts that instructors wish to be studied. For example, the Reacting to the Past series is a widely-used history pedagogy offering a series of published games where students adopt roles informed by classic texts in the history of ideas, such as the restoration of democracy to Athens (Olwell and Stevens 2015). A review of IR simulation learning scholarship finds that many simulation case studies are historical, fictitious or very limited in geographical scope or by issue area. Such historical case studies include events in the lead up to World War I (Arnold 2015; Bridge and Radford 2014) and the Cuban Missile Crisis (Stover 2007). Chasek (2005) designed a simulation based on a fictitious terrorist attack in Singapore during a performance by an Israeli theatre company to illustrate how multilateral diplomacy operates in theory and practice. Chasek (2005) argues that while the specific event was fictitious, it reflected the contemporary concerns of global terrorism in the post-911 era. We contend that fictitious case studies, even mirrored on real life events, are unable to generate the same level of meaningful engagement from students that actual, real-time case studies do. Real-time simulations are crucial in bridging the gap students perceive between academic debate and reality.

Zappile, Beers and Raymond (2017) conducted a real-time simulation addressing the challenges of internally displaced people in post-earthquake Haiti. This example is one that shares the most similarities with our Syrian simulation in terms of its structure, however was conducted across various IR and Political Science subjects in different institutions. While the 
case study is valuable, in comparison to the Syrian civil war it is not as globally 'significant' for introductory IR students. The displacement of Haitians has not generated the same international media attention as the Syrian civil war. In the context of Australian learners, a geographical example such as this is too far removed from the awareness of first-year students. The Council on Foreign Relations (2016) also offers a number of simulation packages, most of which are similarly narrow in focus. By contrast, the complexity of the Syrian case is deeply interconnected with global discourses on refugees and immigration, terrorism and Islamic State (IS). We argue that while there is merit to the above simulation cases, given that they are historical, fictitious or distant from the everyday awareness of introductory IR learners, they are less likely to meaningfully engage large cohorts of first-year students. The Syrian case study and its regional and global implications provide introductory learners with a holistic experience and practical application of most of the fundamental IR concepts needed in a foundational course.

The entire duration of the 13-week semester is dedicated to the simulation activity (see Appendix 1 for Workshop Guide provided to students). Unlike many other role-play simulation exercises in Political Science, the Syrian simulation does not make a 'guest appearance' but is integrated within the subject. Classes consist of twelve 1.5-hour lectures and eight 1.5-hour workshops. The simulated negotiations occur in workshops six and seven, with a mock press conference in workshop 8 to debrief and discuss the related 'authentic' assessment (Policy Memorandum and Reflection). In the preparatory workshop classes leading up to the negotiations, students take part in discussions and debate on the role and structure of the UNSC, debates on UN reform and the veto provision, and the dilemmas of humanitarian intervention and the R2P norm. The workshops then shift to focus directly on the Syrian conflict and refugee crisis. Students are tasked with justifying possible humanitarian options, including small- to large-scale military intervention with a UN peacekeeping operation and political settlement; the establishment of no-fly zones, humanitarian corridors and/or UN safe zones; and refugee evacuation and/or resettlement. The motivations, constraints and consequences of such proposals are analysed and evaluated with students casting a vote to determine which two proposals their workshop class will take into the negotiations. Position papers are provided to students outlining Syria's historical and political background and the key foreign policy principles of each UNSC P-5 member. These position papers do not provide the 'answers' but serve as resources outlining the 
determinants of the respective P-5 members' foreign policy outlook and position on contemporary developments in the Middle East after the 2011 Arab Spring uprisings.

While students choose their humanitarian options in advance of the negotiations, the more intricate logistical details and political conditions comprise the bulk of negotiations during the two simulation classes. Allowing students to actively choose their preferred humanitarian options provides a platform to meaningfully engage with the substance of their proposals; students are challenged to think beyond the perspective of their state as they consider building alliances with others or conceding to demands placed upon them. In the uncertain, fast-paced and often-tense political environment of the simulated negotiations, students experience and come to understand diplomacy and the obstacles in creating a UNSC Resolution. In addition to student groups representing the P-5 members, the simulation design also includes a group of INGO representatives. The role of the INGO group is to lobby the P-5 members to intervene in Syria for humanitarian purposes. They are tasked with convincing the permanent members of the Security Council that it is necessary to take action to ameliorate the humanitarian and refugee crisis under a collective moral responsibility.

\section{Evaluation and Discussion}

\section{Engagement}

We assessed student's responses to the simulation task via a survey instrument (using a fivelevel Likert scale allowing responses of very high, high, average, low and very low), through qualitative comments on anonymous student evaluations of the subject, and in a formal written reflection assignment. A survey of first-year subject convenors within Australia in 2016 revealed that simulation exercises were seldom undertaken in introductory IR classes. This is due to the large cohort sizes at Australian public universities, associated institutional constraints and apprehension about how to design and implement an effective simulation for introductory learners. Some institutions tend to adopt simulations in the second and third year, when class sizes are smaller, students are undertaking their specialisation in Political Science, and it is presumed that foundational knowledge has been gained. The findings from this study strongly support the contention that real-time, role play simulations can be highly effective at engaging students in large introductory subjects. Student feedback on the Syria simulation was overwhelmingly positive and consistent across each cohort with regard to classroom engagement. At the end of each semester, students were asked in the survey 
whether the simulation task was "more engaging and interesting compared with other types of classes" they had experienced. Overall, across our cohorts to date, 89 per cent of students responded with highly or very highly. A similar percentage of 87.5 per cent was reflected in whether the simulation activity was considered to be "more fun and enjoyable" than other classes. These results are shown in Figures 1 and 2 below.

Figure 1: Engaging and Interesting

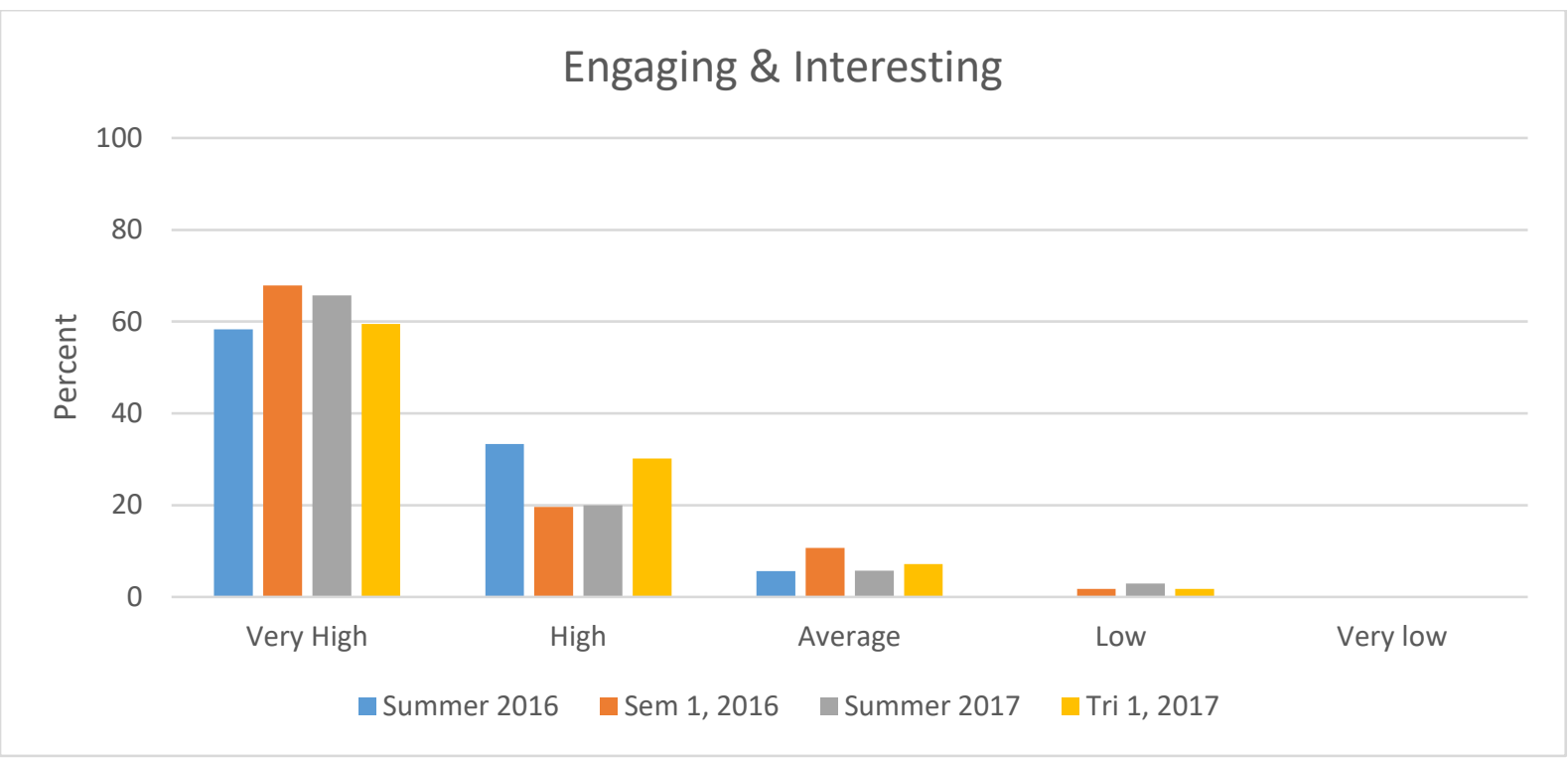

Figure 2: Fun and Enjoyable

\section{Fun \& Enjoyable}

100

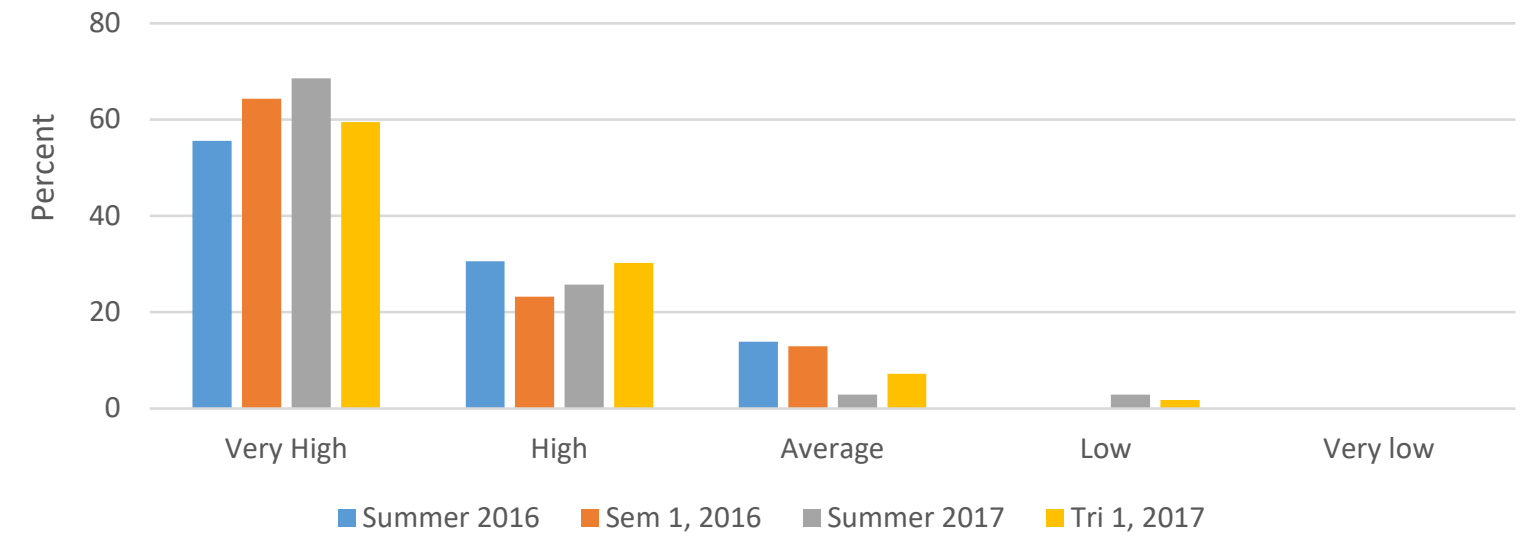


The simulation sparks more interest and greater motivation than other learning environments and tasks by creating an atmosphere that something more important than usual is happening in class. The interplay between collaboration and competition in the simulation adds a heightened sense of tension and excitement to the proceedings. These dynamics in-turn foster increased curiosity in the students, who become intensely interested in what other groups or participants are doing with the content relative to them (Mikalayeva 2016: 216-18). In this respect, one student commented, "This course was probably the most interesting, exciting and fun out of all four that I have participated in this Semester. The simulation exercise made learning topics much easier and enjoyable."

We found that our simulation design, along with the use of customised learning tools and appropriate preparatory and reflective activities, enhanced the learning experience for most students. It does this by creating multiple roles, tasks and responsibilities that are adaptive to variations in student learning styles, preferences and levels of commitment. Students were also able to make friends more easily because of the interactive nature of the task, which engenders a sense of group solidarity. This is very important for first-year students' transition to university life and in building a cohort experience (Vinson et al. 2010: 132). Students commented: "I enjoyed the simulation as it was engaging and encouraged everyone to get involved and to participate;" and "I thoroughly enjoyed the workshops. They were very intense and inclusive and I found I learnt more than I expected to. I was able to make friends easier and it allowed us to express ourselves ... It allowed students all to collaborate and to enjoy themselves with the content from the lectures."

The peer-to-peer learning aspect, where students take ownership and initiative in researching and creating content collaboratively, and progressing the simulation activity, also feeds into the sense of enjoyment. Students take greater responsibility for their learning, because the simulation requires them to take risks and make decisions based on real-time feedback, independently of the instructor. In this respect, another student commented, "The simulation was really well done and very engaging and was a very good way of bringing fellow students together as well as showing the real world ramifications of policies and the complexities of negotiating." We can conclude from the evidence that most students found the simulation enjoyable, meaningful and highly engaging, compared with other learning environments and tasks they had experienced in their studies. 


\section{Deep Learning}

Our next objective was to assess whether heightened engagement translated into deep learning outcomes in the conceptual and metacognitive knowledge domains. For this purpose, we analysed students' formal Reflection assignments where they are encouraged to critically reflect on the structure of the simulation as a classroom activity, and on their learning process in relation to it. Instances of students (1) generalising IR concepts beyond the parameters of the Syria case, and demonstrating (2) metacognitive reflection on their learning process were identified and collated with some examples presented below for illustration. To facilitate these processes, students complete an early reflection worksheet at the beginning of the semester. This worksheet asks students if they follow events occurring in the Syrian conflict; where they source their information from and how often they do so; any emotional responses they may have experienced in relation to the images of human displacement and suffering emerging from the crisis; and the anticipated challenges that the simulation activity may pose for them from both an interpersonal and learning perspective. The purpose of this task is to begin to engage students more deeply in the conceptual and empirical knowledge required to undertake the simulation, and also in the metacognitive knowledge domain of critical reflection on their learning. This task is intended to provide a base-line resource for students in reflecting on their learning process throughout the semester, and also as a way of structuring their Reflection assignment by comparing their position before and after.

In the survey, 86 per cent of students responded that the simulation enhanced their content learning compared with other modes of instruction, as shown in Figure 3 below, and the majority of students were able to apply IR concepts to practice in their Policy Memorandum assignment within the context of the UNSC and Syria case.

\section{Figure 3: Enhance Learning}




\section{Enhance Learning}

100

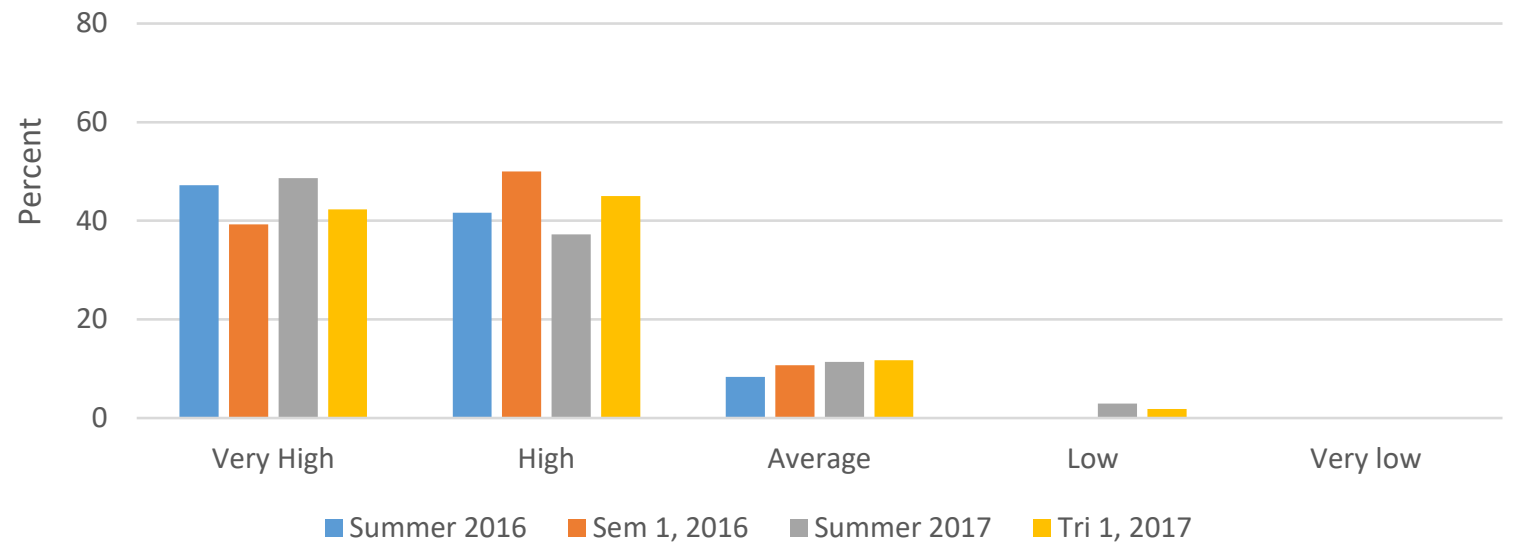

More valuable, our qualitative analysis found that overall, 41 percent of students across the six cohorts demonstrated deep learning outcomes, as defined above, in their written Reflection assignments. This is shown in Table 1 below. In their Reflection document, 30.6 percent of students abstracted conceptual knowledge from the Syria case and applied it to IR more broadly, thus demonstrating a more sophisticated understanding.

Evident also was a marked improvement in these deep learning outcomes for the 2017 cohorts compared with 2016. As shown in the below table, 48.0 percent of the 2017 cohort demonstrated these deep learning outcomes compared with 33.9 percent in 2016.

Table 1: Deep Learning Outcomes, 2016-2017

\begin{tabular}{|l|c|c|c|}
\hline Knowledge Domains & $\mathbf{2 0 1 6}(\mathbf{n = 4 4 7})$ & $\mathbf{2 0 1 7}(\mathbf{n = 3 7 3})$ & Average $(\mathbf{n = 8 2 0})$ \\
\hline Conceptual & $27.3 \%$ & $33.8 \%$ & $30.6 \%$ \\
\hline Metacognitive & $11.7 \%$ & $33.8 \%$ & $22.8 \%$ \\
\hline Totals* & $33.9 \%$ & $48.0 \%$ & $41.0 \%$ \\
\hline
\end{tabular}

*A number of students demonstrated both indicators

We attribute this to improvements made to the pedagogical structure of the subject overall, design of the simulation, guidance provided for students in class and for their assessment, and to our greater experience with facilitating these classes effectively. After the 2016 offerings, students in some instances felt there was a disjuncture between the lecture content and the simulation. For 2017, the simulation was recast as the 'centrepiece' of the subject, 
with the lecture content streamlined and reorganised to provide the necessary historical background, conceptual tools and content knowledge in a more targeted and integrated way. A number of new resources were developed for the 2017 cohort to enhance the learning experience. One of our 2016 simulation classes was filmed and packaged as a learning and teaching exemplar, which was useful in familiarising the 2017 cohort with the task in advance and reducing their uncertainty. A more structured approach was taken with the preparatory classes, with worksheets provided for each. Competitive Kahoot quizzes (an online, gamebased classroom response system played in real-time) were employed for revision of the foreign policy position papers, which also served to foster group solidarity and build excitement. A mock Press Conference was introduced in 2017, which made for a more focused post-negotiations debriefing session

Another perceived weakness in the 2016 simulation structure was the role of the INGO group. This is readily attributable to the simulation prioritising the UNSC as the decisionmaking apparatus. Members of the INGO group at times felt redundant without voting privileges. For 2017, the INGO groups were given clearer instructions, a greater formal role in proceedings and encouraged to participate more extensively in the unmoderated caucus sessions. In the 2017 classes, the INGO groups played more of a 'broker' role between P-5 members-in suggesting potential humanitarian options and the necessary logistics and protection requirements. We suggest that these improvements to the simulation structure and learning environment enabled a greater proportion of students to demonstrate deep learning outcomes.

These claims must remain tentative, however, as the methodological weakness of this study is the lack of a control group that did not undertake the simulation so as to enable a direct comparison of learning outcomes. This weakness is partly due to the evolutionary nature of our approach to this activity, which began primarily with a view to engage large first-year student cohorts of differing learning styles and academic preparedness. It was only after we had conducted the first iterations of the simulation in 2016 that its potential for fostering deep learning outcomes became apparent. Nor is it methodologically sound to make a comparison with the pre-simulation offerings of this subject as the assessment at the time was not explicitly designed to measure deep learning outcomes as defined here, particularly in the metacognitive knowledge domain. Most studies that assess simulations rely on students' self-reported perceptions of knowledge enhancement and suffer from similar 
methodological shortcomings. In seeking to measure the outcomes of active learning more rigorously, two articles conclude that simulations (Raymond 2010) and the "inverted classroom model" (Lambach, Kärger and Goerres 2017) do not improve exam scores in any statistically significant way. Campbell and Cabrera (2014) find similarly that deep learning approaches make no statistically significant difference to students' grade point averages (GPA). While there are many variables to consider in the relationship between deep learning approaches in the classroom and student grades, it is certainly an area that warrants further and sustained attention.

\section{Deep Learning: Conceptual Knowledge Domain}

On the first indicator of applying theory to practice beyond the parameters of the UNSC debate on Syria, three main themes were evident from the qualitative data. One is a greater understanding of non-Western political worldviews in IR. The structure of the simulation forces students to either adopt or understand worldviews foreign to their own country. For instance, it is not often that students in Australia analyse global issues directly from a Chinese or Russian foreign policy perspective. One student commented, "The greatest lesson I found in representing Russia was that for the most part I felt their foreign policy reflected a simple self-interest model that is very evident in the Western nations however nowhere nearly as condemned." Another student commented that:

Roleplaying as China was extremely helpful as it gave me an insight into China's foreign policy that I had never understood before ... Their foreign policy of 'non-interference' and seeking to ensure that sovereignty remains a steadfast principle in international relations made sense to me. I began to realise the implications of the degradation of sovereignty and how China's foreign policy stems from their own past and 100 years of humiliation ... [T] his simulation has broadened my knowledge and changed my view on the world ... it has been a rich experience.

The second theme was a deeper appreciation of the complexity of global issues and the difficulties of diplomacy and collective action. By using the UNSC as a field of operation for great power politics, students could relate to the acute tensions between national interests, international law and humanitarian norms, which with conventional teaching methods can be difficult to grasp. For example, one student remarked, "The immense difficulty of navigating fundamentally opposing foreign policy positions was brought home to me ... Great power dynamics still govern humanitarian decision making, and a rules-based 
international order comes with a range of compromises." The simulation also encourages students to explore the political, economic and normative rationales that guide actors in foreign policy negotiations and decision-making, and how these positions may synergise or not. On this theme, another student reflected:

Although at times frustrating ... these negotiations were the most valuable aspect of the simulation. International relations is fundamentally about power and I think this was obvious during the negotiations-trying to compromise without disregarding national interest and reach a mutually agreeable outcome is difficult. I think the simulation was an excellent practical example of these power politics at play and how complex international issues can get.

The third, more general theme was a deeper understanding of IR concepts. From our experience of teaching introductory $I R$, we observe that many commencing students find the foundational concepts of sovereignty and anarchy abstract, and difficult to understand at first. The simulated UNSC negotiations are very effective in allowing students to directly experience the practical implications of these concepts and hence understand them more deeply. In reflecting on expectations prior to the simulation, the majority of students anticipated learning about UN peacekeeping and the enforcement of international law. Later in the semester, many students commented on the unexpected learning outcomes experienced during the simulation. For example, one student remarked that they were "surprised to discover the difficulty of enforcing international law amongst nations that value state sovereignty ... [this] was a concept I never expected." Another observed that the P-5 "member state groups were more concerned with what they would get out of it [the negotiations], as shown by the fact that the world lives in a state of anarchy due to no world government. I never fully understood ... how much this influences everything."

The Syrian civil war is a case study rich with political, ethnic and religious tensions, therefore providing students with a deeper understanding of the layers of complexity surrounding transnational conflict, civil war and identity politics. One student commented that the "Syrian Civil War case was very useful at explaining the multi-level, multi faction conflicts that are becoming more common place in today's time," while also recognising the more enduring theme that "super power states carry massive influence and often fight ideological battles via the use of smaller weaker states." Another remarked that 
the complex geopolitics surrounding the Syrian civil war provided an interesting foundation for exploring the fundamental concepts of international relations. The large number of regional players allowed me to gain a valuable insight into the dynamics of power between state and non-state actors and apply my knowledge of transnationalism, learnt from the lectures.

Prior to the simulation, students generally fail to appreciate the structural and legal constraints in the international system against humanitarian intervention. We found that students are often incredulous when it becomes clear that the UNSC, as the institution charged with maintaining international peace and security and upholding human rights, consists of states which are deeply implicated in the Syrian civil war. This is compounded when students come to realise these states are also divided by competing national interests, making effective humanitarian action extremely difficult, even with widespread acceptance of the R2P norm. For example:

Being actually able to negotiate with people and running into the difficulties of sovereignty, R2P, the limitation of international law and how politics for some countries trumps human life was very effective. It was very eye opening to experience how difficult it can be to come to an agreement just to provide aid for civilians.

These responses to the simulation illustrate student learning transcending the surface level to deeper understanding. Through experiencing the structural constraints on humanitarian intervention and the limitations of international law, students come to recognise and appreciate the condition of anarchy in the international system and tension between state sovereignty and cosmopolitan norms. These 'light-bulb' moments are challenging to produce for most students in a traditional lecture and tutorial environment but are critical for generating deeper understanding of foundational IR concepts.

\section{Deep Learning: Metacognitive Knowledge Domain}

Role-play simulations are effective as they not only stimulate students at a high-level cognitively, as shown, but also appeal to them emotionally. The below evidence suggests that students' emotional reactions are an important catalyst for metacognitive reflection. We found that the tragic humanitarian consequences of the Syrian civil war made it challenging and emotionally exhausting for many first-year students. On the second indicator of metacognitive knowledge, the main theme that emerged from the qualitative data was students' critical reflection on the tensions between political and moral reasoning in IR, which was often spurred by their emotional responses. Few commencing students enter the 
simulation classes with any knowledge of the UNSC, Syria crisis or context of the Arab Spring uprisings. Their everyday notions of morality tend to be deontological and cosmopolitan. Many students are shocked that something like the Syrian civil war could "still be going on in this day and age" and feel that the international community has a moral obligation to alleviate the human suffering. Numerous students mentioned their alarm and frustration that P-5 member-states would prioritise their own interests over those of people who really need help. For example:

It was extremely frustrating that all countries, including the US, were more concerned with the politics of the negotiations and the enactment of their foreign policy objectives, than providing humanitarian aid and protection for the innocent civilians in Syria. It was extremely hard to believe that countries were prioritising their foreign policy agendas over the human rights of the civilians suffering in Syria.

As this comment suggests, political reasoning can seem quite alien to students at first when confronted with a situation of human suffering. To put it simply, students struggle to 'think like a state'. Consistent with Youde's (2008) simulation of the Darfur conflict, we found that our Syria case tempers student idealism about humanitarianism, encouraging a more nuanced and mature approach that balances compassion with political realities. For example, in succinctly addressing these moral tensions, one student reflected: "I learnt that it is not so much a matter of doing what is right, it is a matter of doing what serves your country and people's best interests." Other student comments also illustrated this finding. For example:

This conflict between my own beliefs and others' actions, did however assist with developing a sense of resilience to P-5 motives and compassion for the Syrian civilians. Participating in the simulation decreased my naivety as it forced me to consider all factors when negotiating.

Having experienced the constraints on humanitarian action first-hand, a proportion of students continued to strongly express empathy and compassion towards the situation, but with a deeper appreciation of the practical difficulties of taking a cosmopolitan approach. One student captured this sentiment in commenting that "states are too self-interested to be 'moral' and I don't believe they will ever intervene for the right reasons." But "people can be driven by compassion and empathy as opposed to self-interest." "Based on the concern I saw in the simulation, I believe that genuine humanitarian intervention can be implemented through compassionate civilians pressuring their governments to act for the right reasons." 
We observed that students representing P-5 members did not anticipate the extent to which their state's foreign policy position would be in tension with their personal moral stance. We found that this 'fractured' students' idealism, disrupting their assumptions about human rights and justice in the world, thus prompting deep moral reflection. This supports the findings of Mayhew et al. (2012) cited above and demonstrates the value of a role play environment that can elicit these responses. The simulation design, with its scaffolded weekby-week structure, provides the mechanism for this. After six weeks of exposure to the Syrian conflict, those students that start out with little knowledge, or enter the class relatively neutral about the humanitarian consequences, are more invested in proceedings and have a personal stake in the outcomes. We observed that is was the emotional conflict between adopting their state or group's position, and their level of personal investment in achieving a humanitarian solution, that provided the catalyst for moral reasoning and deep learning outcomes in the metacognitive domain. This is reflected in the following student comment:

I still struggled on an emotional level with states' policies to not get involved if it affected state sovereignty or their own interests in the country. However, I did feel that I learnt that there is an important balance to be struck between the politics of a matter and human emotion.

Reading about the topic and discussing it in tutorials would not produce similar depth in emotional responses and moral reflection for most students. We infer from the data and our observations that being assigned to role play their state or group generates a heightened level of emotional commitment from students, which is reinforced by a sense of group solidarity. This ensures both a personal and collective stake in the proceedings independent of the instructor and instrumental considerations of grades. The design of the simulation activity thus encourages intrinsic-motivation and a learning environment where larger proportions of first-year students across different learning styles can adopt deep learning approaches.

\section{Reflection and Improvements}

The qualitative data also identified areas of student concern with the simulation design. The most common criticism was that more time was required for the actual simulation sessions: that the two 1.5-hour workshop classes did not allow enough time for deliberation and drafting of Resolutions. We have not sought to change this by adding more time or an additional class. Despite their frustration, we are convinced that students' creativity and 
innovation is stimulated by negotiating and problem solving under the tight time pressures of the existing simulation design.

Approximately 10-15 percent of students across the cohorts rated the simulation as average or less across the survey questions compared with other types of instruction. This finding confirms that active learning of this nature does not suit a minority of students. International students from more traditional educational backgrounds found the simulation classes very difficult, and in some cases, alienating. This was partly due to their level of language proficiency, but also the dissonance between their passive, surface learning expectations and the highly active and autonomous nature of the simulation. Some highachieving upper year level students taking the course as an elective struggled with their formulaic expectations of doing well based on passive teaching approaches applied in other subjects (see also Mikalayeva 2016: 220-222 for a discussion on the negative aspects of active learning). That a minority of students do not realise the benefits of active learning should not discourage the use of simulations. However, along with effective preparatory activities, it does highlight the importance of managing student expectations through clearly articulating the simulation's learning outcomes and why active learning is the chosen pedagogy to achieve those outcomes.

A more substantive area of concern identified is that the simulation in its current structure does not have a Syrian delegation. We recognise that without this the simulation misses the opportunity for local ownership. The inclusion of a Syrian delegation would present the opportunity for students to experience the tensions between international and local ownership in humanitarian assistance. The inclusion of Syrian and other regional actors in the negotiation process would provide a platform for local voices. By also including a Syrian, Iranian, Turkish or Arab League delegation, students could experience not just great power politics between the P-5 members, but also understand how the Syrian conflict impacts key regional players and foreign relations in the Middle East. We have taken the position that this is prohibitive in terms of logistics and complexity at this time. In the existing simulation format, instructors provide these perspectives where appropriate.

\section{Conclusion}

We have sought to demonstrate in this article that 'real-time' role play simulations are not only beneficial for upper year level students but can be highly effective at engaging first-year 
students in large introductory subjects across differing learning styles and levels of academic preparedness. Combined with the nature of the Syria case, this heightened student engagement produced deep learning outcomes across a significant proportion of our cohort. The simulated UNSC negotiations over humanitarian intervention in Syria clearly illustrated to students the acute and sometimes tragic tension between moral and political reasoning in IR. We found that this disrupted many student's cognitive structures regarding human rights and global justice quite profoundly, stimulating not only deeper conceptual understanding, but also emotional reactions that were the catalyst for metacognitive reflection and moral reasoning. Conducting focus groups or student interviews would likely elicit further evidence of deep learning outcomes. Evidence of deep learning could then be correlated with other variables, such as students' learning styles, degree program, gender, socio-economic background, and whether they are international or domestic students. This would provide a richer and more nuanced assessment to better inform our pedagogical approach for future classes.

\section{References}

Arnold, Richard. (2015) Where's the Diplomacy in Diplomacy? Using a Classic Board Game in 'Introduction to International Relations'. PS: Political Science and Politics January: 162-166.

Biggs, John and Catherine Tang. (2011) Teaching for Quality Learning at University: What the Student Does. $4^{\text {th }}$ edition. Maidenhead, UK: McGraw Hill, Society for Research into Higher Education and Open University Press.

Bridge, Dave and Simon Radford. (2014) Teaching Diplomacy by Other Means: Using an Outside-of-Class Simulation to Teach International Relations Theory. International Studies Perspectives 15: 423-437.

Campbell, Corbin M. and Alberto F. Cabrera. (2014) Making the Mark: Are Grades and Deep Learning Related? Research in Higher Education 55: 494-507.

Chasek, Pamela S. (2005) Power Politics, Diplomacy and Role Playing: Simulating the UN Security Council's Response to Terrorism. International Studies Perspectives 6: 1-19.

Council on Foreign Relations. 2016. Case Library. https://modeldiplomacy.cfr.org/\#/cases

Crosling, Glenda and Margaret Heagney. (2009) Improving Student Retention in Higher Education. Australian Universities' Review 51(2): 9-18.

Engel, Susan, Josh Pallas and Sarah Lambert. (2017) Model United Nations and Deep Learning: Theoretical and Professional Learning. Journal of Political Science Education, 
online advance version.

Kahu, Ella R. (2013). Framing Student Engagement in Higher Education. Studies in Higher Education 38(5): 758-773.

Lambach, Daniel, Caroline Kärger and Achim Goerres. (2017) Inverting the Large Lecture Class: Active Learning in an Introductory International Relations Course. European Political Science 16: 553-569.

Lawson, Michael A. and Hal A. Lawson. (2013) New Conceptual Frameworks for Student Engagement Research, Policy, and Practice. Review of Educational Research 83(3): 432-479.

Lantis, Jeffrey S. (2004) Ethics and Foreign Policy: Structured Debates for the International Studies Classroom. International Studies Perspectives 5: 117-133.

Mayhew, Matthew J, Tricia A. Seifert, Ernest T. Pascarella, Thomas F. Nelson Laird and Charles F. Blaich. (2012) Going Deep into Mechanisms for Moral Reasoning: How Deep Learning Approaches Affect Moral Reasoning Development for First-Year Students. Research in Higher Education 53: 26-46.

Mikalayeva, Liudmila. (2016) Motivation, Ownership, and the Role of the Instructor in Active Learning. International Studies Perspectives 17: 214-229.

Oestreich, Joel E. (2012) Teaching Ethics at Drexel: Who, How, and Why? International Studies Perspectives 13: 3-6.

Owell, Russell and Azibo Stevens. (2015) "I Had to Double Check my Thoughts": How the Reacting to the Past Methodology Impacts First-Year College Student Engagement, Retention, and Historical Thinking. The History Teacher 48(3): 561-572.

Pettenger, Mary, Douglas West and Niki Young. (2014) Assessing the Impact of Role Play Simulations on Learning in Canadian and US Classrooms. International Studies Perspectives 15: 491-508.

Ramsden, Paul. (2003) Learning to Teach in Higher Education. $2^{\text {nd }}$ edition. London and New York: RoutledgeFalmer.

Raymond, Chad. (2010) Do Role-Playing Simulations Generate Measurable and Meaningful Outcomes? A Simulation's Effect on Exam Scores and Teaching Evaluations. International Studies Perspectives 11: 51-60.

Stodden, William P. (2012) Simulating Humanitarian Aid Decision Making in International Relations Classrooms. PS: Political Science \& Politics 45(4): 765-771.

Stover, William J. (2007) Simulating the Cuban Missile Crisis: Crossing Time and Space in Virtual Reality. International Studies Perspectives 8: 111-120. 
Taylor, K. (2013) Simulations Inside and Outside the IR Classroom: A Comparative Analysis. International Studies Perspectives 14: 134-149.

Vinson, Don, Sarah Nixon, Barbara Walsh, Cath Walker, Elizabeth Mitchell and Elena Zaitseva. (2010) Investigating the Relationship between Student Engagement and Transition. Active Learning in Higher Education 11(2): 131-143.

Waring, Michael and Carol Evans. (2015) Understanding Pedagogy: Developing a Critical Approach to Teaching and Learning. London and New York: Routledge.

Weber, Linda R. (2013) Deep Learning in the Sociological Classroom: Understanding Craving and Understanding Self. Human Architecture: Journal of the Sociology of Self-Knowledge 11(1): 135-152.

Youde, Jeremy. (2008) Crushing Their Dreams? Simulations and Student Idealism. International Studies Perspectives 9: 348-356.

Zappile, Tina M., Daniel J. Beers and Chad Raymond. (2017) Promoting Global Empathy and Engagement through Real-Time Problem-Based Simulations. International Studies Perspectives 18(2): 194-210. 